\title{
The influence of immediate physiotherapy in the out-patient management of acute knee injuries: a controlled study
}

\author{
M. A. D. PICKARD*, R. M. VENNER*, I. FORD \& \\ B. D. TODD
}

*Accident \& Emergency Department; Department of Orthopaedics, Western Infirmary, Glasgow and, Department of Statistics, University of Glasgow, Glasgow

\section{SUMMARY}

All patients who presented to our Accident \& Emergency Department over a 6-month period with an acute knee injury were randomly assigned to receive either immediate physiotherapy or not prior to further follow up at an out-patient clinic. Patients with trivial injuries not requiring follow up and patients with severe injuries requiring immediate admission were excluded from the study. Patients not immediately referred for physiotherapy could be referred if this was thought neressary at later follow up. There was no statistical difference in the number of outpatient follow up appointments or the length of time to discharge from the clinic between the groups.

Those patients referred for physiotherapy immediately had a significantly greater number of total attendances at the physiotherapy department.

However more patients in the 'no physiotherapy' group ultimately required arthroscopy for suspected meniscal injury. We conclude that a blanket referral of all acute knee injury patients is unjustified and wasteful of resources. However physiotherapy may be indicated in patients initially suspected of having meniscal injury.

\section{INTRODUCTION}

Traditionally, serious injury having been excluded, the acutely injured knee is

Correspondence: Mr B. D. Todd, Registrar, Department of Orthopaedics, Royal Hallamshire Hospital, Glossop Road, Sheffield S10 2JF, U.K. 
immobilized for a period. Discomfort and swelling settle and at subsequent review⿳亠口冋 easier and specific management proceeds.

Trickey (1976) advocates immobilization in the early management of ligament $\overrightarrow{\vec{*}}$ injuries around the knee. He also states that it is best that recovery is slow as? speedy recovery leads to repair with lengthening. Many accident and orthopaedic듬 units, including our own, have adhered to the policy of an initial period of $\stackrel{\bar{c}}{\rightarrow}$ immobilization following acute knee injury.

However this approach has come under strong criticism in recent years. Ryan \&® Allman (1974) feel that rehabilitation following knee injury should begin within $\vec{\circ}$ $24 \mathrm{~h}$ and any delay is a loss of valuable time. It is Riddells (1984) experience that $\overrightarrow{-}$ the loss of bulk and power in the muscle groups around an injured knee which ${ }_{\infty}^{\omega}$ has been immobilized for a few days can take weeks to recover. The work of 3 Noyes (1977) and Akeson et al . (1980) has provided more evidence of the deleterious effects of immobilization.

A number of the physiotherapists in our hospital had expressed the opinion that referral of patients with acute knee injuries to them should be immediate.9 They felt that recovery from such injury would thereby be shortened and the orthopaedic out-patient workload probably reduced. This study was therefore planned to investigate the influence of immediate physiotherapy on the patients attending this hospital with acute knee injuries.

\section{PATIENTS AND METHODS}

All knee injuries presenting within $48 \mathrm{~h}$ to the department were considered eligible⿳亠丷厂犬 for entry to the study. Those patients requiring immediate admission and those $\stackrel{\circ}{\circ}$ patients with injuries thought to be too trivial to warrant follow up were excluded. $\overrightarrow{0}$

A knee injury data sheet was completed for each patient on entry to the trial, 3 usually by the attending accident department $\mathrm{SHO}$ or Registrar. The data included details related to the history of injury and physical signs as well as an initial clinical diagnosis.

All patients were randomly allocated to receive immediate physiotherapy or be managed initially without physiotherapy. Those randomized to receive physiotherapy attended the department immediately for their first treatment or the following morning if they had attended the accident department in the evening.o The prescription of analgesic or anti-inflammatory agents and the provision of support or Robert Jones bandages was not influenced during the course of the trial. The physiotherapiests were informed of the nature of the trial but no attemptro was made to influence the individual physiotherapeutic techniques used or the frequency of attendance at the department. These decisions were left to the discretion of the individual physiotherapist involved.

All patients were reviewed at the specialist knee clinic at 10-14 days posto injury. They were seen and examined by either a consultant (RMV) or a registrar厄్ (MADP, BDT). A knee injury data sheet was again completed (and at all subsequent ${ }^{\text {f? }}$ 
attendances). Those patients who had not initially received physiotherapy were referred for treatment if this was thought necessary. Subsequent follow up was arranged at the discretion of the examining doctor although review after a further 6 weeks was fairly typical. The end point of the trial was defined as either the date on which patients were discharged from the clinic or the date on which their name was placed on the waiting list for an operative procedure (in practice this was always arthroscopy).

The trial was conducted for a 6-month period during which 101 patients were entered as eligible. Of these, 53 were initially diagnosed as having sustained a ligamentous injury, 25 as a possible meniscal injury and the remaining 23 a variety of other conditions. Of the 101 patients entered 46 were prescribed immediate physiotherapy and 55 were not. The two groups were compared by means of a Chi square test for the following data: age, sex, previous injury to the same knee, individual symptoms (pain, swelling, giving way, difficulty weightbearing, locking), individual signs (effusion, quadriceps wasting, localized tenderness and range of movement). In all instances $P>0.05$. The two groups were therefore broadly comparable. In the 'no physiotherapy' group there were 16 defaulters from follow up and in the 'physiotherapy' group there were 14 defaulters.

Table 1 shows the numbers of patients who completed the trial and the mean length of time in the trial for the patients in the two groups. A 2 sample t-test shows no significant difference in the length of time in the trial between the two groups.

Table 2 shows the mean number of out-patient clinic attendances in each group and the mean number of attendances for physiotherapy. A 2 sample t-test again shows no significant difference in the number of out-patient clinic attendances. However there was a significant difference in the number of attendances for physiotherapy between the two groups ( 2 sample $t$-test, $P=0 \cdot 021$. Mann Whitney test, $\mathrm{P}=0.0062)$. Table 2 also shows that of the 71 patients who completed the trial 62 were discharged and nine were placed on the waiting list for arthroscopy. All of the latter group had initial diagnoses made of a possible meniscal injury. Eight out of nine of these patients had not been referred for immediate physiotherapy and only one in nine had.

\section{DISCUSSION}

Measuring recovery from an acute knee injury as the length of time to the patient's discharge from the out-patient clinic is certainly not scientifically precise but is of practical value reflecting morbidity and hospital workload.

This study does not challenge the concept of an individualistic approach to knee injuries as advocated by Stanitski (1985). We accept the evidence that early intervention coupled with the use of judicious immobilization may be the best policy (Montgomery \& Steadman 1985).

However within the personnel and financial limitations of the health service a blanket referral approach is time consuming and therefore costly. Selective referral 
Table 1

\begin{tabular}{lcc}
\hline & Physiotherapy & No Physiotherapy \\
\hline Patients entered & 46 & 55 \\
Defaulters & 14 & 16 \\
$\begin{array}{l}\text { Number completed } \\
\text { trial }\end{array}$ & $32(69.6 \%)$ & $39(70 \cdot 9 \%)$ \\
$\begin{array}{l}\text { Length of time } \\
\text { in trial (mean) }\end{array}$ & 28.6 days & \\
\hline
\end{tabular}

Table 2

\begin{tabular}{lcc}
\hline & Physiotherapy & No Physiotherapy \\
\hline $\begin{array}{l}\text { Number completed } \\
\text { trial }\end{array}$ & 32.00 & 39.00 \\
$\begin{array}{l}\text { Number clinic } \\
\text { attendances (mean) }\end{array}$ & 2.09 & 2.23 \\
$\begin{array}{l}\text { Number physiotherapy } \\
\text { attendances (mean) }\end{array}$ & 6.36 & 3.36 \\
$\begin{array}{l}\text { Number discharged } \\
\text { Number placed on }\end{array}$ & 31.00 & 31.00 \\
waiting list & $1(3 \cdot 1 \%)$ & $8(20.5 \%)$ \\
\hline
\end{tabular}

of patients, following review after a period of rest and immobilization is less se्ष This study indicates our patients are not being neglected.

Although our findings in relation to meniscal injuries are interesting, numbers are small and a larger study is required to ascertain whether early referral for $\stackrel{\Phi}{\circ}$ physiotherapy does significantly influence the natural history of the knee with a $\overrightarrow{0}$ suspected meniscal injury.

\section{REFERENCES}

Akeson W. H., Amiel D., Woo S. L.-Y. (1980) Immobility effects on synovial joints. The pathomechanics of joint contracture. Biorheology 17, 95-100.

Montgomery J. B. \& Steadman J. R. (1985) Rehabilitation of the injured knee. Clinics in Sports Medicine $\stackrel{\circ}{\triangle}$ 4(2), 333-43.

Noyes F. R. (1977) Functional properties of knee ligaments and alterations induced by immobilisation. Clinical Orthopaedics 123, 210-42.

Riddell A. J. (1984) Physiotherapy for sports injuries around the knee. Physiotherapy 70(4), 159-60. Ryan A. \& Allman E. L. (1974) Sports Medicine. Academic press, London. p. 333.

Stanitski C. L. (1985) Rehabilitation following knee injury. Clinics in Sports Medicine 4(3), 495-511. Trickey E. L. (1976) Ligamentous injuries around the knee. British Medical Journal 2, 1492-4. 